\title{
Part 1 Motor Vehicle Craft Studies
}

\author{
Editor R Brooks
}

Name.............
College.......
Employer

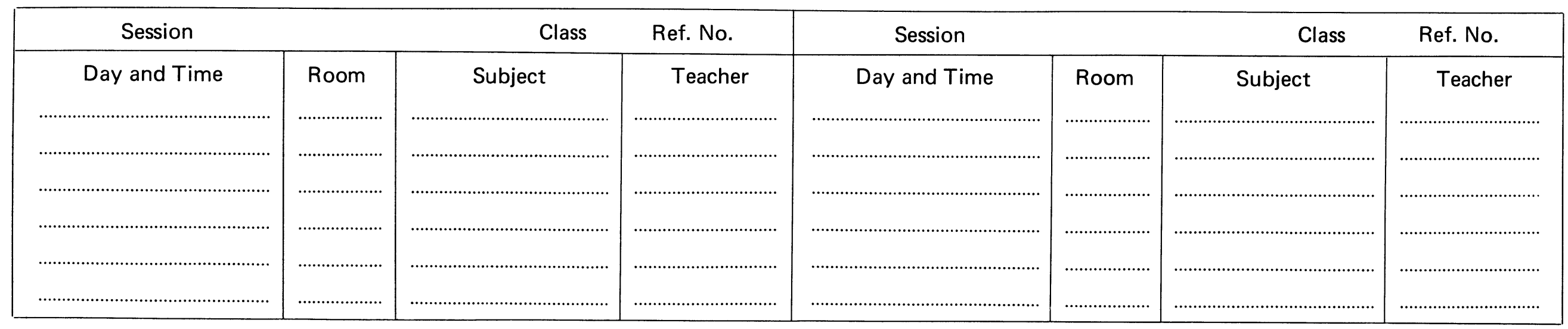




\title{
Macmillan Motor Vehicle Craft Studies Series
}

\section{Part 1 Motor Vehicle Craft Studies}

\author{
Editor $\mathrm{R}$ Brooks \\ Senior Lecturer in Motor Vehicle Subjects \\ Bolton College of Education (Technical) \\ Authors J Hirst \\ Lecturer in Motor Vehicle Subjects \\ Burnley Municipal College \\ $\mathrm{PH}$ Seed \\ Lecturer in charge Motor Vehicle Subjects \\ Nelson and Colne College of Further Education \\ J Whipp \\ Lecturer in Motor Vehicle Subjects \\ Moston College of Further Education
}




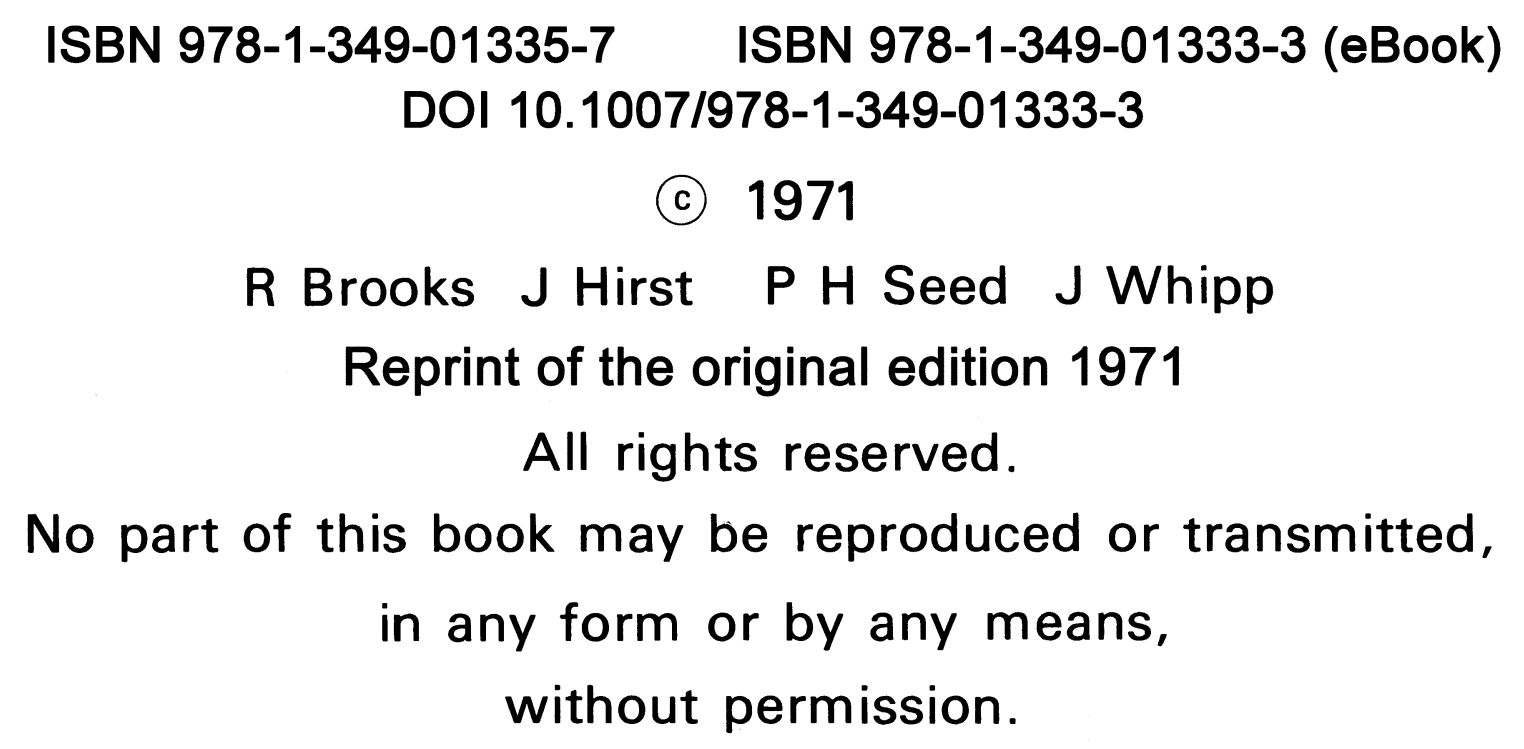




\section{PREFACE FOR STUDENTS}

This book is presented in a style which is completely new in the Automotive field. Its specific aim is to make the task of students taking the Motor

Vehicle Craft Studies Course easier and more rewarding. It does away with the need for several note and text books for the same subject.

The book is unusual in that you are expected to write and sketch in the text A lot of thought has gone into its preparation to cut down the writing to an absolute minimum and make the sketching interesting and useful. Furthermore, much of the information you put into the book can be about vehicles which are of special interest to yourself. This makes it a very worthwhile and valuable record which can be shown to parents or employers as a positive indication of progress.

The book uses primarily the S.I. units of measurement (i.e. a rationalised metric system), except for such specific requirements as conversion tables, B.S.F. threads and the like. However, the layout is such that it enables those requiring Imperial units (as still used by a large proportion of the Motor Trade) to record information and work out problems in the familiar manner; but it will assist towards the progressive transition to S.I. 


\section{PREFACE FOR TEACHERS}

This is a book which is unique in the Automotive field. It has been specifically designed to meet the requirements of the 550 Part I Motor Vehicle Craft Studies Course in a stimulating and interesting manner.

All the information has been carefully structured so as to appeal to the student and encourage him in his studies. He is saved much of the chore of note taking and laborious sketching which in itself can be a considerable obstacle for the less able student. The need for several writing and text books is avoided.

The form of presentation enables teachers to be relieved of many of the less attractive and time-wasting chores of lesson preparation and delivery, yet by the same token enables more time to be devoted to 'real' teaching.

Particular care has been taken to allow-within the confines of the syllabusfor the flexibility of approach so vital to the individual teacher; and also to allow students a certain degree of freedom of choice. However, the layout is such that marking and checking on progress remains simple. Numerous sections could, if thought desirable, be set in place of traditional old-style homework.

In accordance with modern practice the book uses primarily the S.I. units of measurement (apart from certain specific requirements e.g. conversion and British threads). None the less, it is so arranged that those still requiring Imperial units will be able to record information and work out problems in the familiar manner. Furthermore, it will assist towards a progressive familiarisation with S.I. 


\section{ACKNOWLEDGEMENTS}

The authors are indebted to the following firms for their invaluable help with illustrative matter in this book.

British Leyland Motor Corporation

Ford Motor Company Limited

Joseph Lucas Limited 


\section{Contents}

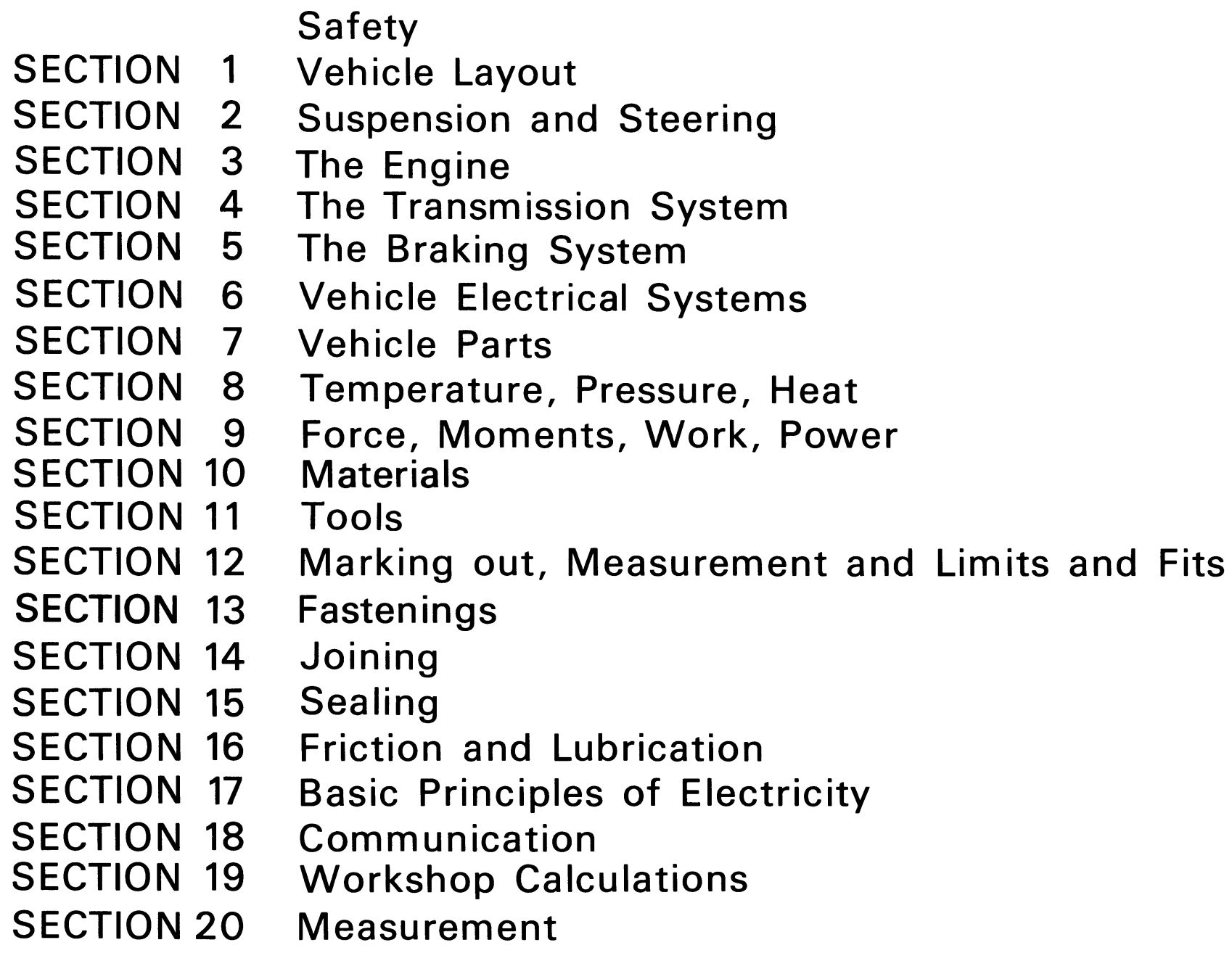

